\title{
ENRAIZAMENTO DE ESTACAS DE AZALÉIA TRATADAS COM CONCENTRAÇÕES DE ANA EM DIFERENTES SUBSTRATOS
}

\author{
Rooting of azalea cuttings treats with NAA concentrations and differents substrates
}

\author{
Munir Mauad ${ }^{1}$, Jose Carlos Feltran ${ }^{1}$, Juliano Corulli Corrêa ${ }^{1}$, \\ Renata Cilene Dainese ${ }^{1}$, Elizabeth Orika Ono², João Domingos Rodrigues ${ }^{2}$
}

\begin{abstract}
RESUMO
De acordo com a necessidade de aumentar a produção de mudas de azaléia por meio da propagação vegetativa, em menor intervalo de tempo, foi proposto estudar os efeitos de diferentes substratos e concentrações de ANA (ácido naftalenoacético). $\mathrm{O}$ experimento foi conduzido em esquema fatorial $3 \mathrm{X} 4 \mathrm{com}$ três substratos (areia grossa lavada, casca de arroz carbonizada e húmus) e quatro concentrações de ANA na forma de pó (0; 2,5; 5,0 e 7,5\%). Utilizaram-se estacas de 100 mm de comprimento retiradas da porção apical do ramo, sem gema apical e com corte em bisel na parte superior, deixando um par de folhas cortadas ao meio. Essas foram colocadas para enraizar em bandejas de isopor de 128 células, por um período de 90 dias, nas quais avaliaram-se: comprimento, superficie, volume e diâmetro radicular e a porcentagem de estacas enraizadas, sobreviventes, mortas e número de brotos. Pode-se concluir que a maior porcentagem de enraizamento foi obtida no substrato de casca de arroz carbonizada e com ANA na concentração de 5\%.
\end{abstract}

Termos para indexação: Rhododendron x simsii Planch, ácido naftalenoacético, enraizamanto, azaléia.

\begin{abstract}
In agreement with to enhancement scion production of Rhododendron $x$ simsii Planch trough the vegetative propagation in shorter time, it was intended to study the effects of different substrates and NAA concentration. The experiment was in factorial design $3 \times 4$ with three substrates (sand, hush rice and humus) and four NAA concentrations in the powder form $(0 ; 2.5 ; 5.0$ and $7.5 \%)$. The cuttings used had $100 \mathrm{~mm}$ length without apical meristem with two leaves cut in half. Those were put to rooting in trays of 128 cells, for 90 days in which were evaluated: length, surface, volume and root diameter and percentage of rooted, surviving and dead cuttings and number the buds. It can be conclued that the greatest of rooting was obtained in the substrates hush rice and the $5 \%$ of NAA.
\end{abstract}

Index terms: Rhododendron $x$ simsii Planch, naphthalene acetic acid, rooting, azalea.

(Recebido para publicação em 28 de julho de 2003 e aprovado em 22 de outubro de 2003)

\section{INTRODUÇÃO}

A azaléia (Rhododendron x simsii Planch.), em razão do efeito decorativo de suas flores, é cultivada em jardins e interiores, sendo propagada comercialmente por meio de estacas, obtendo-se os melhores resultados com a utilização de estacas semilenhosas (Clarke, 1982). Entretanto, o enraizamento é, muitas vezes, difícil, com pequena porcentagem de pegamento, resultando em baixa produção de mudas (Chalfun et al., 1997), o que, segundo Lee (1965), está relacionado ao tipo da espécie a ser cultivada, bem como às condições do ambiente em que são conduzidas, tais como: tipo de substrato, umidade, temperatura, irrigação e luminosidade.

Grande número de fatores, de natureza endógena e exógena, afetam a iniciação e o desenvolvimento de raízes. Entre esses, o balanço hormonal no tecido é a- pontado como de grande importância para o enraizamento (CHALFUN et al., 1997).

Os reguladores vegetais são substâncias endógenas ou sintéticas que influenciam nos processos fisiológicos dessas, em baixíssimas concentrações, modificando quantitativa e/ou qualitativamente o crescimento.

Dos inúmeros efeitos fisiológicos das auxinas nas plantas, a iniciação de raízes é um dos mais comuns, estimulando a desdiferenciação celular. Entre as auxinas sintéticas mais comercializadas, está o ácido naftalenoacético (ANA) (ONO e RODRIGUES, 1996).

As auxinas são mencionadas por diversos autores como efetivas na indução da formação de raízes adventícias, e sua utilização favorece não somente a rizogênese em estacas, mas também permite a melhoria da qualidade do sistema radicular adventício (JARVIS, 1986; BLAZICH, 1988; HARTMANN et al., 1990; LUND et al., 1996).

\footnotetext{
1. Engenheiro Agrônomo, Mc.S, Doutorando, Departamento de Produção Vegetal/Agricultura-Faculdade de Ciências Agronômicas - Caixa Postal 237 - 18609-000 - Botucatu, SP.

2. Universidade Estadual Paulista/UNESP, Professores do Departamento de Botânica, Instituto de Biociências - Caixa Postal 510 - 18618-000, Botucatu, SP.
} 
Lee et al. (1978) compararam o efeito de AIB (ácido indolbutírico), ANA (ácido naftalenoacético), AIA (ácido indolacético) e 2,4-D (2,4 - diclorofenóxi- acético) na formação de raízes em hipocótilo de feijãomungo e verificaram que os melhores resultados foram conseguidos com o uso da auxina sintética ANA, seguido de AIB. Diversos autores comprovaram ser a auxina um importante regulador na formação de raízes (ONO e RODRIGUES, 1996).

Além do balanço hormonal, fatores nutricionais da planta matriz, tais como os carboidratos e condições de enraizamento (CHAFUN et al., 1997), tipo de substrato e componentes associados a esse (ANDRADE NETO et al., 1999) também são apontados como fatores importantes na formação de raízes.

O substrato deve sustentar a estaca durante o período de enraizamento, proporcionar teor de umidade adequado e o espaço poroso ideal facilita o enraizamento e evita o desenvolvimento de doenças, permitindo boa oxigenação próxima à base da estaca, além de apresentar baixa densidade de partículas (COUVILLON, 1988; MARCO et al., 1998; ANDRADE NETO et al., 1999).

Assim, torna-se necessário aumentar a porcentagem de pegamento de estacas de azaléia utilizando-se de forma eficiente os reguladores vegetais associados ao conhecimento das características dos substratos, para que se possa obter mudas de qualidade em menor tempo. Para tanto, objetivou-se com este trabalho avaliar as melhores concentrações de ANA e diferentes substratos no enraizamento de estacas de azaléia.

\section{MATERIAL E MÉTODOS}

O experimento foi conduzido no Setor de Horticultura do Departamento de Produção Vegetal da Universidade Estadual Paulista - Campus de Botucatu, no período de abril a junho de 2000 . Ramos de azaléia foram coletados no mês de abril e as estacas foram retiradas da porção apical, sendo padronizadas com comprimento em torno de $100 \mathrm{~mm}$, deixando-se um par de folhas cortadas ao meio, sem gema apical e com corte em bisel na parte inferior.

As estacas foram tratadas com benomyl, na concentração de $4 \mathrm{~g} \mathrm{~L}^{-1}$ do produto comercial Benlate e, em seguida, receberam as concentrações de $0 ; 2,5 ; 5,0$ e 7,5\% de ácido naftalenoacético (ANA) na formulação de pó. Posteriormente, foram colocadas para enraizar em três diferentes substratos: areia grossa lavada, casca de arroz carbonizada e húmus, sendo acondicionadas em bandejas de isopor de 128 células e $12 \mathrm{~cm}$ de pro- fundidade e mantidas em câmara de nebulização. O sistema de nebulização era acionado por "timer" e programado para manter a umidade relativa do ar em aproximadamente $100 \%$. As irrigações eram realizadas a intervalos de 10 minutos durante 1 minuto.

$\mathrm{O}$ delineamento experimental utilizado foi inteiramente casualizado em esquema fatorial $3 \mathrm{X} 4$, sendo três substratos, quatro concentrações de ANA e quatro repetições, cada parcela contendo 16 estacas, totalizando 768 estacas.

As avaliações foram realizadas aos 90 dias após a implantação do experimento, observando-se: porcentagem de estacas com raízes, de estacas sobreviventes, de estacas mortas e de brotos. As análises físicas dos substratos foram determinadas segundo a metodologia proposta por Silva (1998), sendo determinados os percentuais de arejamento, retenção de água e porosidade total.

As estacas que apresentavam raízes foram separadas, as raízes, retiradas e acondicionadas em recipientes plásticos com solução de álcool a $30 \%$ e armazenadas em ambiente refrigerado, para as seguintes avaliações: comprimento total, área superficial, volume total e diâmetro médio das raízes, as quais foram estimadas por meio de leitura ótica com scanner e uso do software Win Rhyzo V.3,8.

Os resultados de porcentagem de estacas com raízes, de estacas sobreviventes, de estacas mortas e de brotos foram submetidos à análise de variância (teste F), sendo as médias comparadas pelo teste Tukey a 5\% de probabilidade. Esses dados foram transformados segundo $\sqrt{x+0,5}$. Já os resultados para comprimento de raízes formadas, superfície, volume e diâmetros de raízes foram submetidos à análise de regressão.

\section{RESULTADOS E DISCUSSÃO}

Em função dos resultados apresentados na análise de regressão, houve efeito significativo das concentrações de ANA entre os diferentes substratos no desenvolvimento das raízes em estacas de azaléia. Nota-se que a casca de arroz carbonizada apresentou os melhores resultados para comprimento, superfície, volume e diâmetro radicular, quando comparado com areia e húmus, exceto para o diâmetro radicular na maior concentração de ANA (7,5\%), em que esses proporcionaram maiores valores para essa variável, como será apresentado.

Os melhores resultados encontrados para o substrato casca de arroz carbonizada ocorreram provavelmente pelo fato de esse substrato apresentar menor den- 
sidade $\left(0,61 \mathrm{~kg} \mathrm{dm}^{-3}\right)$ proveniente da maior porcentagem de macroporos, demonstrado pela variável arejamento (Tabela 1). Assim, esse substrato propicia melhor escoamento do excesso de água e favorece o desenvolvimento radicular.

O substrato húmus com maior retenção de água e porosidade (Tabela 1) proporcionou maior porcentagem de estacas mortas (Tabela 2), provavelmente por causa da menor presença de oxigênio, condição essa desfavorável para o crescimento radicular.

A taxa de infiltração de água é afetada pelo volume de poros, ao passo que a retenção de água é afetada pelo número e distribuição dos poros pela superfície específica (BETTIOL e CAMARGO, 2000). Brawer e Camargo (2000) encontraram melhor enraizamento em casca de arroz carbonizada para estacas de sucupira-preta, devido a maior retenção de água, contrariando os resultados apresentados neste estudo, pois o melhor enraizamento com casca de arroz é atribuído à capacidade intermediária dessa na retenção de água em relação ao substrato húmus e areia grossa (Tabela 1).

Outro fator que contribuiu para o enraizamento é a presença de folhas nas estacas. Hartmann et al. (1990) afirmam que principalmente em espécies de difícil enraizamento a presença de folhas estimula o enraizamento, visto que as auxinas não são os únicos fatores responsáveis pela rizogênese, necessitando de outros fatores que normalmente são produzidos pelas folhas $\mathrm{e}$ gemas fisiologicamente ativas (CHALFUN et al., 1997).

Na Figura 1 observou-se efeito positivo entre o aumento das concentrações de ANA, para comprimento radicular no substrato areia e na casca de arroz carbonizada, com a máxima resposta calculada em 7,5 e 4,2\%, respectivamente, ao passo que, para o húmus, esse efeito não foi significativo. Esses resultados corroboram com Lee et al. (1978) e Ono e Rodrigues (1996), que encontraram efeito positivo da auxina no enraizamento de estacas de feijão-mungo, cafeeiro e quiuí.

TABELA 1 - Valores médios de densidade, arejamento, retenção de água e porosidade de três substratos utilizados no enraizamento de estacas de azaléia. Botucatu, UNESP, 2000.

\begin{tabular}{ccccc}
\hline Substratos & Densidade & Arejamento & Retenção de Água & Porosidade \\
\hline Areia & $\begin{array}{c}\left(\mathrm{kg} \mathrm{dm}^{-3}\right) \\
2,03 \mathrm{~A}\end{array}$ & $2,8 \mathrm{C}$ & $7,4 \mathrm{C}$ & $10,2 \mathrm{C}$ \\
\hline $\begin{array}{c}\text { Casca de arroz } \\
\text { carbonizada }\end{array}$ & $0,61 \mathrm{C}$ & $34,2 \mathrm{~A}$ & $17,6 \mathrm{~B}$ & $51,8 \mathrm{~B}$ \\
\hline Húmus & $1,01 \mathrm{~B}$ & $17,3 \mathrm{~B}$ & $42,2 \mathrm{~A}$ & $59,5 \mathrm{~A}$ \\
\hline $\mathrm{CV}(\%)$ & 2,45 & 3,18 & 2,44 & 2,45 \\
\hline
\end{tabular}

Letras comparam resultados dos substratos.

Médias seguidas de mesma letra não diferem significativamente entre si, pelo teste Tukey. 
TABELA 2 - Porcentagens de estacas com raízes, sobreviventes e mortas e número de brotos, referentes à parte aérea das estacas de azaléia, com 90 dias, em função de concentrações de ANA e tipos de substrato. Botucatu, UNESP, 2000.

\begin{tabular}{|c|c|c|c|c|c|}
\hline Tratamentos & ANA & $\begin{array}{c}\text { Estacas com } \\
\text { Raiz }\end{array}$ & $\begin{array}{c}\text { Estacas } \\
\text { Sobreviventes }\end{array}$ & Estacas Mortas & Número de Brotos \\
\hline & & -------------- & $\%$ & ----- & \\
\hline \multirow{4}{*}{ Areia } & 0 & $66 \mathrm{Ab}$ & 93 Aa & $7 \mathrm{Ba}$ & $5,66 \mathrm{Ba}$ \\
\hline & 2,5 & 79 Aab & $97 \mathrm{Aa}$ & $3 \mathrm{Ba}$ & $6,39 \mathrm{Ba}$ \\
\hline & 5,0 & $87 \mathrm{Aab}$ & $99 \mathrm{Aa}$ & $1 \mathrm{Ba}$ & $6,67 \mathrm{Ba}$ \\
\hline & 7,5 & $97 \mathrm{Aa}$ & $100 \mathrm{Aa}$ & $0 \mathrm{Ba}$ & $7,23 \mathrm{Ba}$ \\
\hline \multirow{4}{*}{$\begin{array}{l}\text { Casca de arroz } \\
\text { carbonizada }\end{array}$} & 0 & $86 \mathrm{Ab}$ & $99 \mathrm{Aa}$ & $1 \mathrm{Ba}$ & 7,51 Aa \\
\hline & 2,5 & $95 \mathrm{Aab}$ & $100 \mathrm{Aa}$ & $0 \mathrm{Ba}$ & 7,87 Aa \\
\hline & 5,0 & $100 \mathrm{Aab}$ & $100 \mathrm{Aa}$ & $0 \mathrm{Ba}$ & 7,57 Aa \\
\hline & 7,5 & $100 \mathrm{Aa}$ & $100 \mathrm{Aa}$ & $0 \mathrm{Ba}$ & 7,55 Aa \\
\hline \multirow{4}{*}{ Húmus } & 0 & $46 \mathrm{Bb}$ & $30 \mathrm{Ba}$ & $70 \mathrm{Aa}$ & $2,65 \mathrm{Ca}$ \\
\hline & 2,5 & $67 \mathrm{Bab}$ & $50 \mathrm{Ba}$ & $50 \mathrm{Aa}$ & $4,92 \mathrm{Ca}$ \\
\hline & 5,0 & $77 \mathrm{Bab}$ & $55 \mathrm{Ba}$ & $45 \mathrm{Aa}$ & $5,13 \mathrm{Ca}$ \\
\hline & 7,5 & $85 \mathrm{Ba}$ & $60 \mathrm{Ba}$ & $40 \mathrm{Aa}$ & $5,03 \mathrm{Ca}$ \\
\hline $\mathrm{CV}(\%)$ & & 17,3 & 15,2 & 37,6 & 21,06 \\
\hline
\end{tabular}

Letras minúsculas comparam resultados de cada substrato, e letras maiúsculas os comparam entre os substratos.

Médias seguidas de mesma letra não diferem significativamente entre si, pelo teste Tukey, ao nível de $5 \%$ de probabilidade.

O aumento das concentrações de ANA favoreceu o aumento da superfície de raiz, com a máxima resposta calculada em 7,71; 3,83 e 7,5\%, para os substratos areia, casca de arroz carbonizada e húmus, respectivamente, conforme verifica-se na Figura 2. Segundo Galle (1995), o uso de reguladores vegetais para enraizamento não foi essencial para a maior parte das cultivares de azaléia, porém, quando na presença dessas, induzem a formação de raízes mais rapidamente e com maior uniformidade, como demonstrado pelo incremento da área de superfície de raiz, com o aumento das concentrações de ANA (Figura 2).

Para a variável volume de raízes (Figura 3), os melhores resultados foram obtidos na concentração de ANA a 4,35 e $3,14 \%$ para os substratos areia e casca de arroz carbonizada, respectivamente, ocorrendo queda acentuada a partir dessa concentração, enquanto para o substrato húmus, houve crescimento mais pro- nunciado a partir da concentração de $2,93 \%$ de ANA, obtendo-se maior volume de raízes na concentração de $7,5 \%$.

Efeito positivo foi observado para a variável diâmetro médio de raízes, para húmus e areia; no entanto, o mesmo não ocorreu para casca de arroz carbonizada, em que o diâmetro médio apresentou efeito negativo (Figura 4). Isso se deve provavelmente ao fato de que o enraizamento em casca de arroz carbonizada apresentou maior desenvolvimento primário, expresso pelo maior comprimento (Figura 1) em relação ao crescimento lateral, representado pelo diâmetro (Figura 4). Os menores diâmetros são responsáveis pela maior absorção, o que pode ser comprovado pelo maior número de brotos e porcentagem de estacas sobreviventes no tratamento com casca de arroz, que provavelmente foram nutridos por essas raízes (Tabela 2). 


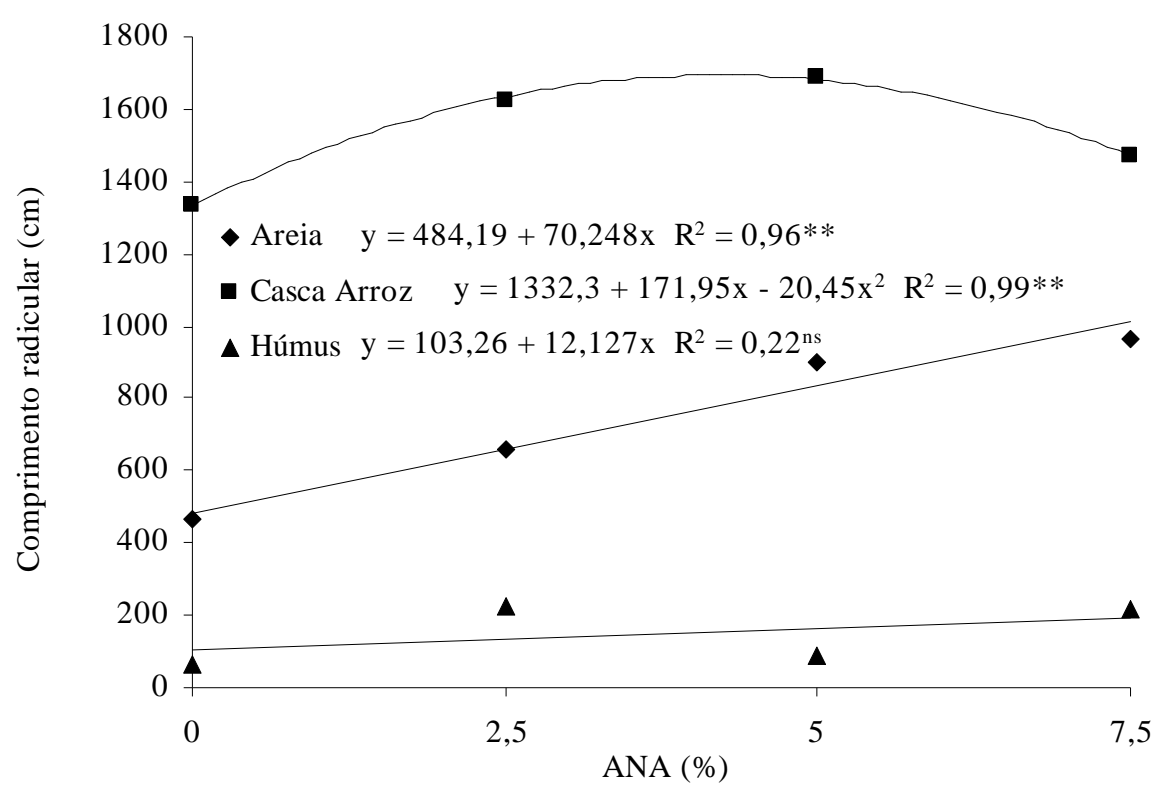

FIGURA 1 - Comprimento radicular de estacas de azaléia, em função das concentrações de ácido naftalenoacético (ANA) e três tipos de substratos. Botucatu, UNESP, 2000.

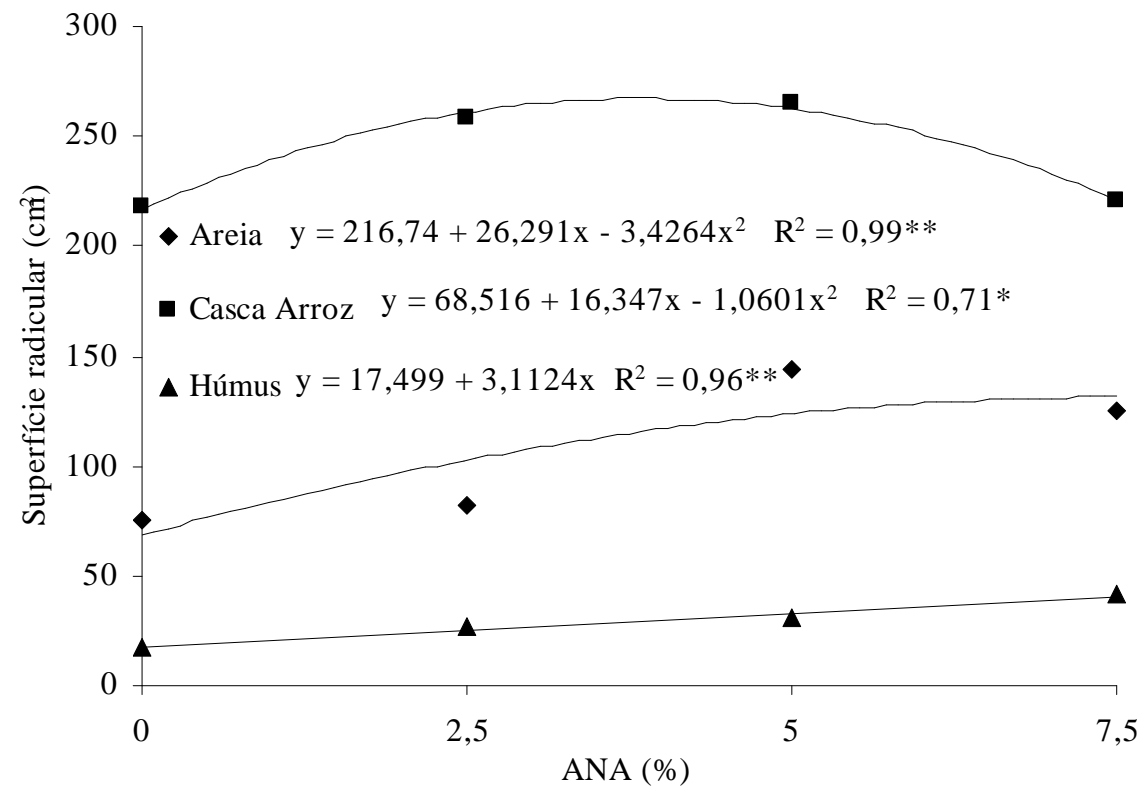

FIGURA 2 - Superfície radicular em estacas de azaléia, em função das concentrações de ácido naftalenoacético (ANA) e três tipos de substratos. Botucatu, UNESP, 2000. 


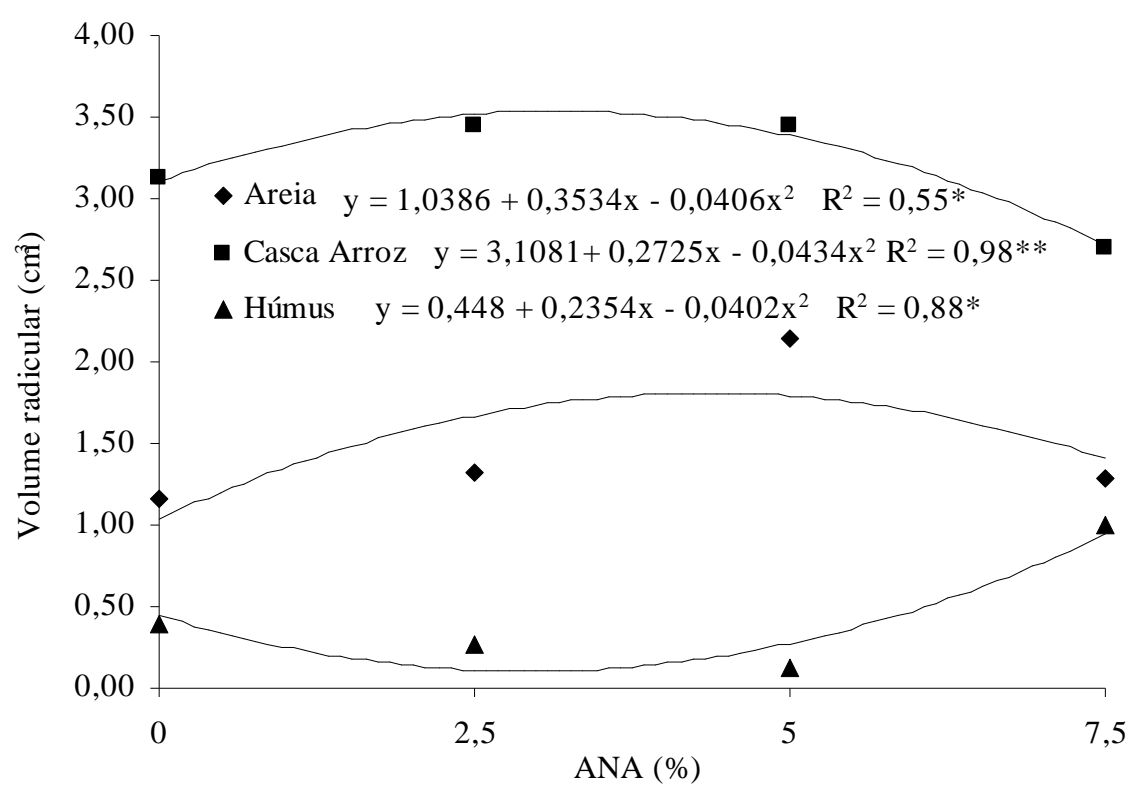

FIGURA 3 - Volume radicular em estacas de azaléia, em função das concentrações de ácido naftalenoacético (ANA) e três tipos de substratos. Botucatu, UNESP, 2000.

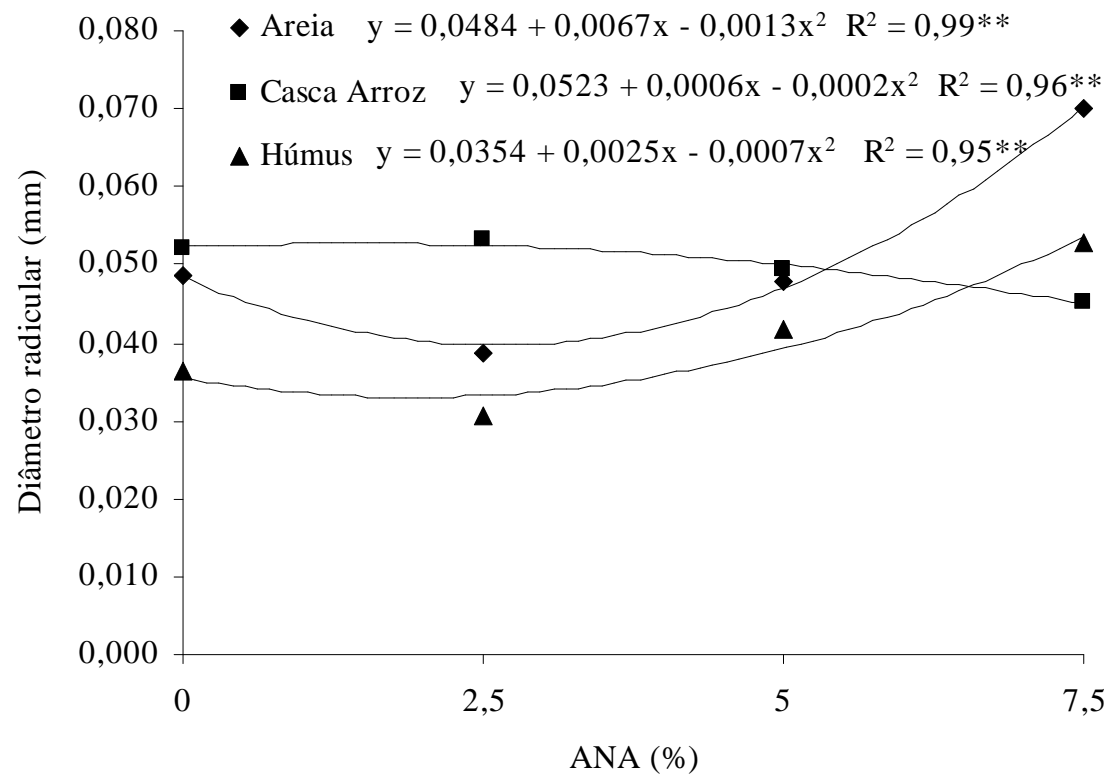

FIGURA 4 - Diâmetro radicular em estacas de azaléia, em função das concentrações de ácido naftalenoacético (ANA) e três tipos de substratos. Botucatu, UNESP, 2000. 


\section{CONCLUSÕES}

Com base nos resultados obtidos e nas condições deste experimento, pode-se concluir que a melhor concentração de ANA foi de 5,0\% para o enraizamento de estacas de azaléia, e o substrato casca de arroz carbonizada apresentou o melhor desempenho em razão de sua menor densidade e maior arejamento.

\section{REFERÊNCIAS BIBLIOGRÁFICAS}

ANDRADE NETO, A.; MENDES, A. N. G.; GUIMARÃES, P. T. G. Avaliação de substratos alternativos e tipos de adubação para a produção de mudas de cafeeiro (Coffea arabica L.) em tubetes. Ciência e Agrotecnologia, Lavras, v. 23, n. 2, p. 270-280, 1999.

BETTIOL, W.; CAMARGO, O. A. Impacto ambiental do uso agrícola do lodo de esgoto. Brasília, DF: EMBRAPA, 2000. 312 p.

BLAZICH, F. A. Chemicals and formulation used to promote adventitious rooting. In. DAVIS, T. D.; HAISSIG, B. E.; SANKHLA, N. (Eds.). Adventitious root formation in cuttings. Portland: Dioscorides, 1988. p. 131-149.

BRAWER, L. R.; CAMARGO, I. P. de. Efeito de substrato sobre o desenvolvimento de mudas de paratudo e sucupira preta. In: CONGRESSO BRASILEIRO DE OLERICUlTURA, 40., 2000, São Pedro. Anais... São Pedro: SOB, 2000. p. 892-893.

CHALFUN, N. N. J.; HOFFMANN, A.; CHALFUN, A. J.; JESUS, A. M. dos S. Efeito da auxina e do anelamento no enraizamento de estacas semilenhosas de azaléias. Ciência e Agrotecnologia, Lavras, v. 21, n. 4, p. 516-520, 1997.

CLARKE, J. H. Gentting started with rhododendrons and azaleas. Portaland: Timber, 1982. 268 p.
COUVILLON, G. A. Rooting responses to differents treatments. Acta Horticultirae, Wageningen, v. 227, p. 187-196, 1988.

GALLE, F. C. Azaleas. Portland: Timber, 1995. 519 p.

HARTMANN, H. T.; KESTER, D. E.; DAVIES JUNIOR, F. T. Plant propagation: principles and practices. 5. ed. Englewood Cliffs: Prentice-Hall, 1990. 647 p.

JARVIS, B. C. Endogenous control of adventitious rooting in non-woody cuttings. In. JACKSON, M. B. (Ed.). New root formation in plant and cuttingns. Dordrecht: Martinus Nijhoff, 1986. p. 191-222.

LEE, J. D. The azalea book. Tailandia: [s.n.], 1965. $461 \mathrm{p}$.

LEE, L. S.; CHEN, Y. M.; LIN, C. W. Studies on the formation of adventitious roots initial in mung bean hypocotyl. Taiwania, Taipei, v. 23, p. 115-122, 1978.

LUND, S. T.; SMITH, A. G.; HACKETT, W. P. Cuttings of tabacco mutant, rac, undergo cell divisions but do not initiate adventitious roots in response to exogenous auxin. Physiologia Plantarum, Copenhagen, v. 97, p. 372-380, 1996.

MARCO, C. A.; KERSTEN, E.; SILVA, J. G. C. da. Influência do ethephon e do ácido indolbutírico no enraizamento de estaca de ramos de goiabeira (Psidium guajava L.). Ciência Rural, Santa Maria, v. 28, n. 2, p. 221-224, 1998.

ONO, E. O.; RODRIGUES, J. D. Aspecto da fisiologia do enraizamento de estacas caulinares. Jaboticabal: UNESP, 1996. 83 p.

SILVA, M. R. da. Características morfológicas, fisiológicas e nutricional de mudas de Eucalyptus grandis Hill ex. Maiden submetidas a diferentes níveis de estresse hídrico durante a fase de rustificação. 1998. 120 f. Dissertação (Mestrado em Engenharia Florestal) - Universidade Federal do Paraná, Curitiba, 1998. 